\title{
Research and Analysis of Perforating Cable Fishing Technology
}

\author{
Liping Qu \\ Market development center of oil testing and production branch, China \\ quliping@petrochina.com.cn
}

\begin{abstract}
Perforation gun and cable are stuck underground, which often occurs in cable perforation. Whether the perforation cable gets stuck properly or not will not only affect the cost of accident treatment, sometimes even affect the success or failure of a well, and sometimes delay the best time of other well layout; Therefore, the unblocking and fishing technology of perforating gun is an important part of perforating operation. The fishing operation of perforating gun sticking can be divided into two categories: one is the fishing of cable, the other is the fishing of perforating gun body. The shape of fish falls into rope and tube. The stuck fishing work must accurately grasp: well condition data, fish falling situation, fishing tool combination, fish head situation, etc. Combined with the process of accident treatment, this paper studies and analyzes the fishing technology of perforating cable and perforating gun.
\end{abstract}

Keywords: Perforated cable, External hook fishing spear, Internal hook fishing spear, Overshot

\section{Introduction}

The development of society can not be separated from the support of energy. Therefore, oil production has been widely concerned. The problem of falling objects in wells is a common problem that puzzles oil production. The concept of downhole falling objects in oil fields is broad, mainly referring to a variety of tangible materials falling from oil production wellhead, pipe string, logging and other devices. According to the shape, they can be divided into pipe well falling objects, rope well falling objects, rod well falling objects, etc. These wells must be cleaned up in time, otherwise once the oil layer is blocked, the threat to the entire oil well will be fatal. There are two main methods for cleaning the falling objects in the well. One is to destroy it in the well, but the more extensive method is to use the technique of downhole fishing.

\section{The basic strategy of rope salvage}

\subsection{External hook fishing of movable teeth}

The pipe string combination from bottom to top is: movable tooth external hook+adjusting nipple $(3 \sim$ $4 \mathrm{~m}$ ) +hemispherical baffle (diameter less than $2 \sim 4 \mathrm{~mm}$ of casing inner diameter)+pipe string.

Operation method: when the drilling tool is lowered to $10 \mathrm{~m}$ above the top of the fish, rotate at the bottom. When the tension meter shows that the hanging weight of the drilling tool decreases, continue to apply force for rotation, and then lift it up to observe the change of the hanging weight and judge the fishing effect.

If the ropes in the well have become a group, the outer hook can be moved when the outer hook cannot be inserted. Because when this kind of external hook is blocked, the movable hook retracts into the hook body, so that the hook body is easily inserted into the rope-like falling mass. When lifting the pipe string, the movable hook is opened by the elastic force of the spring to hang the rope falling objects.

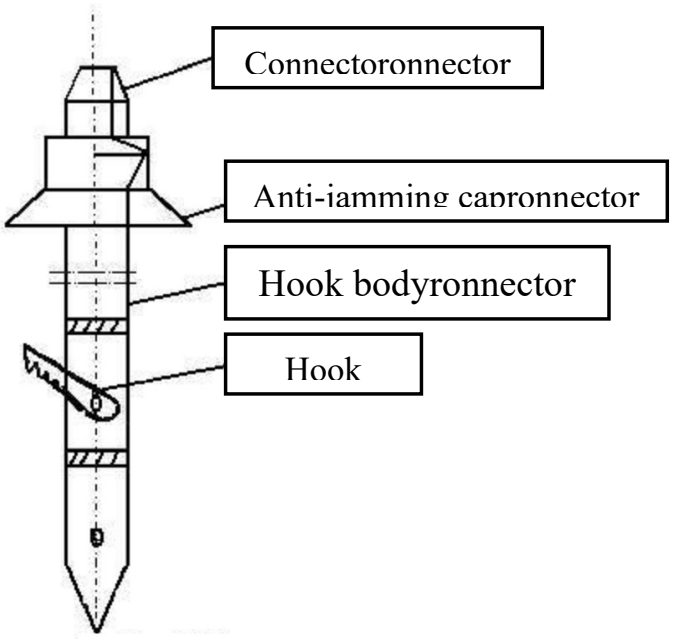

Fig. 1. The elastic force of the spring to hang the rope falling objects.

\footnotetext{
* Corresponding author: quliping@petrochina.com.cn
} 


\subsection{Double arm internal hook fishing}

The combination of the pipe string from bottom to top is: double-arm outer hook + adjusting sub $(3 \sim 4 \mathrm{~m})+$ hemispherical baffle (diameter less than the inner diameter of the casing $2 \sim 4 \mathrm{~mm})+$ pipe string.

Operation method: Lower the drilling tool slowly when it is lowered to $10 \mathrm{~m}$ above the fish top. When the hanging weight drop is observed from the weight indicator, use the methods of lifting and lowering, rotating and changing the direction for fishing. Requirements: anti falling device shall be installed at the wellhead to prevent falling objects under the well; The downhole tools shall be identified by a specially assigned person to ensure that they are solid and reliable.

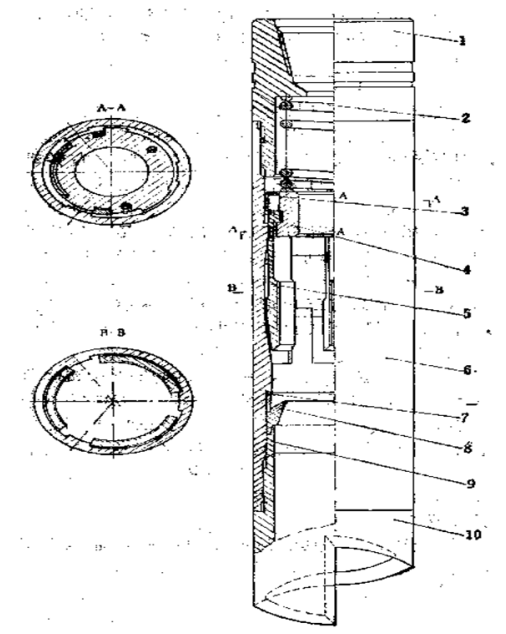

Fig. 2. The downhole tools shall be identified by a specially assigned person to ensure that they are solid and reliable

\section{Basic fishing strategy of perforating gun body}

\subsection{Buckling barrel:}

It can not only be used for fishing and make-up, but also release fish, but also circulate well washing fluid. In the fishing operation, the inverted fishing drum is one of the important supporting tools of the inverted tool, and can also be used together with the inverted drill pipe.

Principle of action:(1) Lower the tool to the top of the fish drop, rotate the tool, and introduce the fish drop. When the slip with an inner diameter slightly smaller than the outer diameter of the fish falls into contact with the fish, the cylinder begins to slide down relative to the slip, the spring is compressed, and the limit sits on the lower end face of the upper joint, forcing the slip to expand outwards, and the fish enters the slip. Because of the spring force, the teeth of the slip always cling to the outer surface of the fish. If the drilling tool is lifted up after the lowering is stopped, the cylinder moves upward relative to the slip. As the slip fits with the cone of the cylinder, the clamping force of the three slips on the falling fish increases with the increase of the lifting force; The triangular teeth eat into the outer wall of the falling fish. Continue to raise, and salvage can be realized.
(2)If torque is applied to the drill pipe at this time, it will be transmitted to the slips and the fish through the key on the barrel, so that the fish joint will be loosened, that is, the undercut will be realized.

(3)If fishing and back-off fail, if you want to quit fishing and retrieve the tool, you can relax and knock down the drilling tool to make the slip separate from the cone surface of the cylinder, then turn right, and the inner chamfer at the bottom of the slip enters the included angle of the inward inclined plane, locking the slip on the cylinder and rotating with the cylinder. You can exit the fish by lifting the drill string.

\subsection{Retractable slip overshot:}

Structure of slip overshot: slip overshot is basically composed of outer barrel and internal components. The same outer cylinder can be used with slips of different sizes to operate fish of different sizes. The outer cylinder is mainly composed of an upper joint, a main body and a shoe guide. The spiral slip is composed of packing, spiral slip and control ring; the basket slip is mainly composed of basket slip and milling shoes.

Working principle: the fishing part of the overshot is screw slip or basket slip. Its external wide serrated thread and internal fishing tooth are left-hand threads. The clearance between the wide sawtooth thread and the cylinder is large, which makes the slip expand and shrink within a certain stroke in the cylinder. As long as an axial pressure is applied, the falling fish can enter the slip. With the insertion of the falling fish, the slip rises and expands. Under the action of elasticity, the slip teeth bite the falling fish. When the drill string is lifted up, the slip moves downward in the barrel, the diameter is reduced, and the falling fish is caught more firmly. Because the threads of the cylinder and the slip are lefthanded threads, and their rotation is restricted by the control ring, when releasing the fish, just loosen the slip and rotate the drilling tool clockwise, and the fishing cylinder can be withdrawn from the fish.

Salvage steps:

(1)Circulating fish head: record the circulating pressure of low pump stroke $(30 \sim 50 \mathrm{SPM})$ before fishing. It is estimated that about 0.5 meters above the fish top, the fish top will be washed with large displacement. Flush the fish head with a fixed low pump. When the suspension weight becomes smaller, immediately stop the brake lever. Record the depth of the well when it encounters resistance or when the pump pressure rises, that is, the position of the fish top.

(2)Fishing: slowly lower the drilling tool, pressurize 4.9 to $49 \mathrm{kn}$, put the fish head into the barrel, confirm the insertion depth, and then upper the drilling tool. If the suspended weight increases, it is proved to catch the falling fish.

(3)Treatment after fishing: After fishing, the fish can be lifted from the bottom of the well by 0.5 to 0.8 meters, and braked twice or three times. If the hanging weight does not drop, it is proved that the fish has been caught before tripping out. If not, the above operations can be repeated. 
(4)Tripping out: after successful fishing, due to the control of tripping out speed, it is better to use hydraulic tong to break out. It is strictly prohibited to rotate the rotary table. When the fish is pulled out of the wellhead, clean the overshot with clean water. After the fish falls out of the well, try to avoid dismantling fishing tools at the wellhead to prevent the fish from falling into the well again.

\section{Perforating cable and perforating gun fishing examples and fishing technology research analysis}

When perforating well zq-52 in 2016, the lifting cable was stuck when the construction was carried out to the ninth shot and the depth was $2574 \mathrm{~m}$. Party A decided to use the bottom cutter string to go into the well to cut off the cable lower bottom cutter string. It can't continue to descend down to 2037 meters, and the cable is broken when it is lifted up.

Penetration point of perforating vehicle: $2037 \mathrm{~m}$. $537 \mathrm{~m}$ cable, $4 \mathrm{~m} 102$ gun and 3M 102 empty gun are left in the well.

a. The first salvage pipe string (movable tooth fishing spear): down to the 217 th, depth: $2084.49 \mathrm{~m}$, the hanging weight of the pipe string is reduced from $13 \mathrm{t}$ to $8 \mathrm{t}$, the string is rotated 13 times, and the pipe is lifted to the 212 th. The weight rose from $13 \mathrm{t}$ to $17 \mathrm{t}$, returning to normal tonnage instantly.

Pull out all fishing strings and pull out cable $40 \mathrm{~m}$.

b. The second salvage pipe string (live-tooth fishing spear): down the $\Phi 73 \mathrm{~mm}$ EUE tubing down to the 221st, depth: 2122.76 meters, the hanging weight of the pipe string is reduced from 13 tons to 3 tons (big hook weight) and rotate 15 times forward, slowly Lifting, lifting to the 213th, the hanging weight of the pipe string rose from 13 tons to 15 tons, after 15 minutes of maintaining the hanging weight of 15 tons, slowly raising to 17 tons, the hanging weight returned to normal (13t).

Lift the fishing string and fish out the cable for $50 \mathrm{~m}$.

c. The third salvage pipe string (outer hook fishing spear-73mm tubing welding system): down $\Phi 73 \mathrm{~mm}$ EUE tubing down to the 223rd, depth: 2149.84 meters, the hanging weight of the pipe string is reduced from 19 tons to 10 tons (big hook weight) Spin 20 times, slowly lift up to the 215 th, the suspended weight of the pipe string rises from 19 tons to 23 tons, and slowly rises to 23 tons, and the suspended weight returns to normal (19t).

Lift the fishing string and fish out the cable for $20 \mathrm{~m}$.

d. Lower the fourth fishing string (external hook Spear $73 \mathrm{~mm}$ oil pipe welding): $\Phi 73 \mathrm{~mm}$ eue tubing runs down to the $222 \mathrm{nd}$, depth: $2140.28 \mathrm{~m}$, string hanging weight is reduced from $19 \mathrm{~T}$ to $15 \mathrm{t}$, positive rotation is 10 turns; Slowly lower the pipe string, and the hanging weight of the pipe string is reduced from 15 tons to 10 tons, with positive rotation of 20 turns. Slowly lower to the No.223rd pipe, with a depth of $2,149.84 \mathrm{~m}$, and the hanging weight of the pipe string is reduced from 10 tons to 7 tons and rotated for 10 times; Slowly lift it up to the No.215th pipe, and the hanging weight of the pipe string rises from 19 tons to 23 tons. Continue to slowly lift it up, and the hanging weight returns to normal.

Lift the fishing string and fish out the cable for $30 \mathrm{~m}$.

e. The fifth trip to salvage the pipe string (live-tooth fishing spear): down the $\Phi 73 \mathrm{~mm}$ EUE tubing down to the 225th, depth: 2168.98 meters, the hanging weight of the pipe string slowly decreases from 19 tons to 3 tons (hook hanging weight). Lift and lower the movable pipe string, down to the 227 th tubing, with a depth of 2180.16 meters. The pipe string cannot continue to descend. Slowly lift the pipe string. The suspended weight is increased from 3 tons to 10 tons and rotated 15 times. No change in tonnage (normal hanging weight 19 tons), start the pipe.

Lift the fishing string and fish out the cable for $12 \mathrm{~m}$.

f. Lower the sixth fishing string (external hook fishing spear - 38mm oil well pump welding): $\Phi 73 \mathrm{~mm}$ EUE tubing was run down to the 227 th, and the string hanging weight was slowly reduced from $19 \mathrm{~T}$ to $16 \mathrm{t}$, with 15 turns of forward rotation; The suspended weight of the pipe string is slowly reduced from $16 \mathrm{t}$ to $12 \mathrm{t}$, and the forward rotation is 15 turns; The hanging weight of the pipe string is slowly reduced from 12 tons to 9 tons, and the forward rotation is 15 turns. Slowly lift up the pipe string, and there is no change in tonnage (normal suspended weight of 19 tons), and lift the pipe.

Lift the fishing string and fish out the cable $42 \mathrm{~m}$.

g. Lower the seventh fishing string (external hook fishing spear - 38mm oil well pump welding): $\Phi 73 \mathrm{~mm}$ eue oil pipe is lowered to the 230th (square entry: $0 \mathrm{~m}$ ), the hanging weight of the pipe string is slowly reduced from 19 tons to 12 tons, and the forward rotation is 15 turns. The depth is $2200.61 \mathrm{M}$. The hanging weight of the pipe string decreased slowly from 12 tons to 8 tons (square in 2 meters) and rotated 15 times with a depth of 2,202.61 meters; Slowly lift the pipe string to 227 , and after the lifting tonnage (normal hanging weight of 19 tons) rises to $23 \mathrm{t}$, return to normal tonnage (19t), and pull out the pipe.

Lift the salvage pipe string, the hanging weight of the pipe string suddenly rises to $35 \mathrm{t}$ at the start and stop 150 , and then returns to the normal tonnage of $19 \mathrm{t}$. The pipe string is lifted out, and the outer hook fishing spear ( $38 \mathrm{~mm}$ oil pump welding) is pulled off $(5.5 \mathrm{~m}$ tools are left in the well) .

h. Run the fishing string (movable tooth spear) on the eighth trip: lower $\Phi 73 \mathrm{~mm}$ eue tubing was run down to the 150th, and the string hanging weight decreased slowly from $10 \mathrm{t}$ (normal hanging weight) to $2 \mathrm{~T}$, with 15 turns of forward rotation; Slowly lift up the string, restore the normal tonnage (19T) and start the pipe.

Lift the fishing string and fish out the cable for $30 \mathrm{~m}$.

The lead mold of the perforating car: the length of 1497.5 meters from the platform.

i. Lower the ninth fishing string (inner hook spear): $\Phi$ $73 \mathrm{~mm}$ eue oil pipe down to the $162 \mathrm{nd}$, depth: $1554.16 \mathrm{~m}$. The tonnage of pipe string is reduced from $15 \mathrm{t}$ to $14 \mathrm{~T}$; Lift the hanging weight of the string to 16t; Pipe lifting. Trip out the fishing string and fish out the cable for about $343 \mathrm{~m}$ (the perforation marks are marked, and the perforation personnel judge that it is broken from the cable head). 
j. The next tenth salvage pipe string (windowed overshot): Lower the $\Phi 73 \mathrm{~mm}$ EUE tubing down to the 268th, and the hanging weight of the pipe string decreases slowly from 22 tons (normal hanging weight) to 20 tons and rotates forward for 5 times, and slowly raises the highest tonnage. After rising to $30 t$, the normal tonnage $(30 \mathrm{t})$ will be restored, and the pipe will be started.

The fishing string was lifted and no tools were fished out. Punch the lead mold with the perforating car, and the depth is $2570 \mathrm{~m}$. The fish top is shown as a $38 \mathrm{~mm}$ pump cylinder.

k. Run the fishing string on the 11th trip (reverse fishing barrel): lower $\Phi 73 \mathrm{~mm}$ eue tubing is lowered to the 268 th, with a depth of $2572.16 \mathrm{~m}$. The string hanging weight is slowly reduced from $22 \mathrm{~T}$ (normal hanging weight) to $21 \mathrm{t}$, and the string is rotated forward for 2 turns; Slowly lower the string to $12 \mathrm{t}$ and suddenly rise to 16t (fish jacking tool); Continue to slowly lower the string to 4T; Slowly lift up the string, go up 4m, the tonnage rises to $38 \mathrm{t}$, and suddenly falls back to $22 \mathrm{~T}$ (normal tonnage); Slowly lower the pipe string for $1 \mathrm{~m}$, and if there is resistance indication, start the pipe.

Fishing string: pull out $38 \mathrm{~mm}$ pump spear tool.

1. run the 12th fishing string (retractable slip overshot): Lower the $\Phi 73 \mathrm{~mm}$ EUE tubing down to the 269th, depth: $2574 \mathrm{~m}$, the suspended weight of the tubing string decreased slowly from 22 tons (normal suspended weight) to 4t; slowly lift the tubing string, no tonnage change; continue to slowly lower the tubing string to $12 \mathrm{t}$ and suddenly rise to $16 \mathrm{t}$ (fish top into the fishing bucket); continue to slowly lower the pipe string to $4 \mathrm{t}$; slowly lift the pipe string, the hanging weight of the pipe string rises to $40 \mathrm{t}$, suddenly drops to $22 \mathrm{t}$ (normal tonnage), and the pipe is started.

Fishing string: successfully fished out the perforation gun body.

Research and Analysis on fishing technology for the fishing process of the well:

(1) The upper part of all fishing tools into the well is equipped with a $\Phi 118 \mathrm{~mm}$ spacer ring to prevent the cable from running up.

(2) The length of the movable tooth fishing spear is $1.75 \mathrm{~m}$, the cable is inserted into the positive rotation, the pipe string of the pressurized part is suspended, and a small amount of cable is gathered, so the efficiency value of the movable tooth fishing spear is reduced.

(3) The outer diameter of the outer hook fishing spear ( $\Phi 73 \mathrm{~mm}$ tubing welding) is too large compared to the movable tooth fishing spear, and the gap between the spear and the casing is narrow, which is not conducive to cable gathering and cable fishing.

(4) External hook fishing spear (welded by $38 \mathrm{~mm}$ oil well pump) $\Phi 38 \mathrm{~mm}$ oil well pump welded, anchor claw $\Phi 19 \mathrm{~mm}$ sucker rod, oil well pump and sucker rod toughness fishing cable are completely OK. However, when the sucker rod anchor claw is planted and welded on the oil well pump body, there will be a thin weakness. When the cable is wound on the upper part of the fishing spear, the lifting of the pipe string will produce a clutching phenomenon, the hanging weight of the pipe string will increase significantly, and then it will be pulled off from the weak point of the fishing spear.

(5) Window-opening fishing barrel is suitable for fishing irregular fish, and the broken fishing spear has an anchor claw, which is not conducive to opening the window and completely entering the fish; The window fishing barrel is too thin to apply heavy load.

(6) The inverted bailer has different application ranges, and the slip in the bailer used in this well is suitable for $\Phi$ For the fishing of $73 \mathrm{~mm}$ oil pipe, $21 \mathrm{~mm}$ thick tooth block is welded on the slip through processing, which is completely suitable for the fishing of external hook fishing spear (welded by $38 \mathrm{~mm}$ oil well pump).

(7) When the fishing barrel approaches the fish top, it is best to rotate slowly so that the fish top can completely enter the fishing barrel; Increasing the tonnage may lead to the destruction of the top of the fish, making it impossible to salvage in the next step.

\section{Conclusions}

(1) Scientific analysis and correct fishing ideas are very important for fishing with multiple falling objects.

(2) For the fishing of flexible falling objects such as cables, the position of fish top shall be judged as far as possible to prevent excessive lowering and compaction of cables or ineffective construction.

(3) For objects with different outer diameters in the well, fishing tools of corresponding sizes should be selected.

(4) According to the actual situation, the effective selection of corresponding technologies and methods can effectively save time in the construction process and successfully fish the falling objects. Whether it is pipe or rope falling into the well, a good combination of methods can always salvage it effectively.

\section{References}

1. Ma Manhong. Research on the salvage technology of falling objects in oilfield wells[J]. Chemical Management, 2013(10): 114-114.

2. Fan Longwen. Discussion on the technology of salvaging complex falling objects underground[J]. Henan Science and Technology. 2013(5)

3. $\mathrm{Wu}$ Qi. Handbook for Downhole Operations Engineers Beijing: Petroleum Industry Press. 2002:215-253

4. Ren Fade. Discussion on the method of salvaging falling objects in oilfield downhole operations [J]. Petrochemical Technology. 2016, 23 (8): 260 